\title{
Seeing is believing? Experiences of using systematic social observation as an evaluation method
}

\author{
\begin{tabular}{c}
\hline Rick Brown \\
Australian Institute of Criminology \\
Rick.Brown@aic.gov.au \\
\hline
\end{tabular}
}

Keywords: Systematic Social Observation, observational methods in evaluation, environmental campaign evaluation, alcohol licensing evaluation, street based observation, night time economy observation, environmental visual audits.

\begin{abstract}
In conducting project evaluations there are often times when data are not available and where standard methodologies are not always appropriate or sufficient. In some cases, there can be benefit in applying Systematic Social Observation (SSO) to gain an understanding of how a project is working. This paper explores the use of simple forms of SSO as an evaluation method in such circumstances. Based on case studies from the UK involving evaluating the impact of changes in alcohol licensing laws and evaluating the impact of environmental clean-up campaigns, this paper explores design issues, problems experienced by fieldworkers and the benefits to be gained from employing SSO.
\end{abstract}

\section{Introduction}

There are times in undertaking evaluation studies when data collected for routine administrative purposes prove to be unavailable or unreliable, or when other forms of data collection provide too partial a picture, or are simply too impractical to apply in a given situation. In such circumstances, systematic social observation (SSO) may provide a useful, additional means for understanding how a particular, program, project, initiative or intervention is being implemented. Indeed, as Mastrofski, Parks and McClusky (2010) noted, "SSO may be especially desirable when the question demands detailed knowledge of situations, conditions or processes that are not otherwise wellilluminated or where there is reason to question the validity of knowledge based on other forms of observation." (p. 228)

SSO is defined here as the routine recording of an observed event or situation, allowing for the collection of predetermined variable categories or metrics in a standardised way. The key attributes that SSO seeks to attain are reliability (the same event should 
be recorded in the same way every time) and replicability (the observation study should produce similar results if it were to be repeated). As such, SSO can be contrasted with other, more ethnographic or qualitative forms of observation which may focus on interpreting observed phenomena (Fetterman, 2010).

SSO has previously been used to collect information on a range of issues. For example, Reiss (1971) described the characteristics of SSO studies, based on his policing research and, indeed, the approach has continued to be used in policing studies (Mastrofski et al. 1998, 2010; McCluskey \& Terrill, 2005; Schelnberg, 2014; Terrill \& Reisig, 2003). Its use has also been extended to other fields of enquiry, including observations of the night-economy economy (Hough, Hirschfield \& Newton, 2008; Homel, Carvolth, Hauritz, Mcllwain \& Teague, 2004; Sim, Morgan \& Batchelor, 2005; Smith, Morgan \& McAtamney, 2011), neighbourhood characteristics (Odgers Caspi, Bates, Sampson \& Moffitt, 2012; Sampson \& Raudenbush,1999; Sampson, Morenoff \& Gannon-Rowley, 2002), behaviour assessment (Briesch, Chafouleas \& Riley-Tillman, 2010), school environments (Wilcox, Augustine \& Clayton, 2006) and physical activity (Zarrett, Sorensen \& Skiles, 2010) to name just a few.

SSO as described in this paper focuses on gaining a quantitative representation of a particular event or situation. This can be particularly useful for examining how a situation changes over time, following the introduction of a particular intervention. This paper draws on the experiences of the author in undertaking SSO of different kinds of events and situations and aims to draw out both the benefits of the approach and the problems experienced when applying the approach in the field.

\section{Background to the studies}

This paper draws on two sets of studies that applied simple forms of SSO techniques in different ways, all of which were undertaken in the UK between 2005 and 2009. The first set of studies examined the impact of changes in one particular night-time economy ${ }^{1}$ (Hartlepool, in the north-east of England) following the introduction of the Licensing Act (2003). The Act introduced a range of changes to the way in which alcohol licenses were regulated, generally liberalising the drinking environment. In particular, it increased the flexibility over opening times of licensed premises, paving the way for the potential for 24 hour opening. Two studies were undertaken in Hartlepool to gain an understanding of the workings of the night-time economy (see Brown \& Evans, 2011). The first occurred in 2005, prior to the Act being occurred in 2005, prior to the Act being implemented in November of that year.

1. The 'night-time economy' refers to leisure activity that takes place in and around entertainment districts / town centres during the evening and early hours of the morning. This typically involves activities such as dining out, consuming alcohol in bars and clubs, visiting the cinema / theatre etc. See Hadfield (2006) for an account of the rise of the night-time economy in Britain. 
Among the research methods employed were street-based observations of the night-time economy over four weekends (Friday and Saturday nights). A further study in November 2009 again employed street-based observations, although over one weekend only?

The street-based observations were designed to gain a quantitative picture of an evening in Hartlepool. These were undertaken as part of a suite of data collection methods that included interviews with stakeholders, a survey of local residents, a survey of visitors to the night-time economy and an analysis of crime and disorder data provided by the police and the fire and rescue service. The purpose of the street-based observations was to document a typical evening in Hartlepool and to create a kind of 'natural history' of changes over the course of an evening. This kind of information was not available from existing documentary sources and the second-hand accounts of others frequenting the night time economy were considered insufficient for drawing conclusions about the workings of the night-time economy. In addition, an important aspect of the work was to examine how a night-time economy changed following the introduction of new legislation, especially in terms of the numbers of patrons frequenting the area at different times of the evening. SSO techniques were considered to be the only reliable means of assessing these changes over time.

The observation study used a data collection tool that collected information on a number of undesirable features associated with the night-time economy, including the number of discarded bottles and glasses on the street, the number of items of rubbish, the number of visibly drunk people (later dropped as a data item), the number of fights, evidence of people vomiting and evidence of public urination. Contextual information associated with the number of men and women on the street and the presence of the police were also recorded. The fieldwork involved two teams of two researchers, with one team observing each of the two main streets that formed the night-time economy area. The observation involved walking down one side of the street and then returning along the other side of the street. Each data collection cycle would take about 15 minutes. This was repeated every half an hour during the course of the evening. The researchers carried a mechanical counter in each hand (which were stowed away in their coat pockets to avoid drawing attention). These were used to count the most voluminous items - one researcher would count the number of men and the number of discarded bottles / glasses, while the other would count the number of women and the number of items of rubbish. The remaining data items were mentally recorded by both researchers and agreed upon at the end of the data collection cycle.

Ethical considerations were raised about the use of SSO in this study. However, the risks to those being observed were considered to be minimal and outweighed by the gains (in terms of knowledge acquisition) for a number of reasons. Firstly, the unit of analysis focused on the night-time economy at a particular point in time, rather than on individuals and as a result, no individual could be identified from any of the data collected. Secondly, the data collection focused on the public spaces (the streets) and did not include privately owned spaces, such as inside pubs / clubs, which could have raised more serious concerns regarding informed consent from venue managers. Thirdly, the approach of not engaging with those frequenting the night-time economy 
area meant that the process of data collection would have no discernible impact on those being observed.

A greater concern related to the safety of researchers operating in an area where there was a higher than average risk of random violence. This was addressed by researchers working in pairs, with a senior staff member supervising the work on the street at all times, who could make a judgement about whether conditions were suitable for the researchers to continue to operate over the course of the evening.

The second set of studies involved evaluating the effectiveness of clean-up operations undertaken by Community Safety Partnerships ${ }^{3}$. These were designed to improve the physical environment of local communities by removing rubbish and graffiti. Evaluations associated with ten separate clean-up operations between 2006 and 2008 involved an environmental visual audit both pre and post clean-up (Brown \& Evans, 2012). The visual audits were undertaken within one week of the clean-up commencing and within a week following the clean-up. This approach to data collection was employed as it was considered to be the only reliable and cost-effective way of measuring the outcome from a clean-up operation. Alternatives, such as surveying the local community pre and post intervention were considered too imprecise (due to the difficulties of assessing perceptions of environmental change over short periods of time) and too resource intensive.

The environmental visual audits involved two researchers walking through an area designated for the clean-up and recording details of rubbish and graffiti observed in the area. Information collected on each 'incident' included the time, date and description of the item, a description of the location and the location on a map. A photo would also be taken of the 'incident'. The team later developed an application that ran on a Personal Digital Assistant (the forerunner of smartphones), which automatically photographed and plotted the GPS location of the 'incident'. There were no ethical issues considered to be problematic in these studies as the unit of analysis focused on the consequences of human endeavour (discarding rubbish), rather than any direct observation of activities - whether that be the clean-up operation workers collecting rubbish or local residents discarding rubbish.

2. This change in methodology was at the request of the client. Indeed, the 2009 study had a slightly different emphasis with a street-based survey of patrons being deployed as the main form of data collection.

3. In 2007, the Home Office promoted the concept of Weeks of Actions. These were multi-agency, multiple intervention initiatives, that typically incorporated a significant environmental clean-up component. An example of one such initiative in Nottinghamshire, England, which reported the removal of 343 tonnes of rubbish, was submitted for a Tilley Award. Further details can be found at www. popcenter.org/library/awards/tilley/2007/07-41.pdf (accessed 12th April 2014). 


\section{Experiences of employing SSO}

The experiences of using SSO are described here in terms of the design issues associated with the methodology and the experiences of employing SSO in the field.

\section{Design issues associated with SSO}

The key design issues of concern with SSO were associated with sampling, reliability and generalisability. Other design issues noted in the literature were not relevant in these studies. For example, reactivity, in which observed subjects act differently because of the presence of a researcher has been noted as a significant risk in SSO studies, although generally considered to decline as fieldwork progresses (Mastrofski et al. 1998, 2010; Reiss, 1971; Shulenberg, 2013). The need to build rapport with observed subjects has also been noted as important (Reiss, 1971). In the studies described here, the observation focused on the environment, rather than on individuals, thereby avoiding the issues of reactivity and rapport.

The current studies were also at the complete observation end of the participant observation scale (Hagan, 1982), with no interaction required between the researcher and the subject of the observation (the environment), thereby limiting to a minimum the potential for bias to be introduced by the presence of the researcher. However, as noted later, in some circumstances this proved harder than expected. McCall (1978) has noted that this approach to participant observation can involve a trade-off between unobtrusiveness and the ability to ask questions about what is being observed. In the studies examined here, this was considered to be of minimal concern, given that the focus was more on recording what was observed, rather than understanding why.

\section{Sampling}

Sampling in both sets of studies was based on geography and time. In the case of the night-time economy studies, two streets in Hartlepool town centre were sampled as the principal location for pubs and clubs in the town. Fieldwork focused on Friday and Saturday nights, which reflected the time when restaurants, bars and clubs in the area were at their busiest. In the first study, fieldwork was undertaken between 8pm and 3am on each evening. Taking account of the changes in opening hours following the implementation of the Licensing Act (2003), the second study involved fieldwork between $10 \mathrm{pm}$ and $5 \mathrm{am}$. The unit of analysis in these studies was a thirty minute time interval, with the aim of developing a picture of how the night-time economy area changed over the course of an evening.

In the environmental clean-up studies the sampling frame consisted of particular geographical locations (usually areas of high social housing) at which clean-up operations had been undertaken. Two points in time were sampled - a day within one week of the commencement of the clean-up operation and the same day of the week following 
completion of the operation. The same day of the week was sampled to account for the impact that regular refuse collection might have on the build-up of rubbish in an area. The unit of analysis in these studies was an item of rubbish or graffiti.

\section{Reliability}

Reliability in SSO studies relies (at least in part) on the observation and interpretation skills of the researcher to record data accurately against a pre-defined set of variables. As Mastrofski et al. (1998) noted, this can become problematic when observers are required to interpret and classify behaviour. For example, in studies of police practice, it proved easier to code the responses to questions such as 'Did the police handcuff the citizen?', than to code questions such as 'Were the police justified in handcuffing the citizen?' (Mastrofski et al.1998, p. 9).

In the night-time economy studies, most of the variables collected were dichotomous, based on a simple presence or absence of an issue. This avoided the need to make judgements that would have been necessary had scaled variables been used. However, one problem arose in relation to counting the number of drunk people observed on the street. It became apparent early in the fieldwork that it was difficult to discern from a distance whether someone was drunk unless they exhibited clear behaviour as such. There was also a degree of relativity to the measure. At $8 \mathrm{pm}$ it was easier to judge someone as drunk if their behaviour stood out as different from others. At 2am the judgement was more difficult when standards of behaviour generally seemed to have declined. A decision was therefore made to drop the requirement to count drunk people from the data collection form.

Concerns with inter-rater reliability have previously been noted in observation studies of the night-time economy, especially where different fieldworkers have been used to collect information on different nights. For example Miller et al. (2012) described how checks were made to detect significant discrepancies, and also conducted simultaneous quality assurance observations on $10 \%$ of observations. In the Hartlepool studies, inter-rater reliability was addressed by a mix of simplifying the measures to be counted, agreeing findings between researchers and using the same fieldworkers consistently over different nights.

In the environmental clean-up studies, measurement was based on the presence or absence or rubbish/graffiti. Rubbish was coded as:

- General litter - small items (cans, bottles, packaging) such as one might find in a public litter bin.

- Small fly-tips - accumulations of two or more small items such as rubbish sacks, tyres, old televisions etc.

- Large fly-tips - larger accumulations of waste in a location, such as might constitute a car load of rubbish for example. 
- Large items - one or more bulky household goods such as sofas, chairs, fridges etc.

- Other - items that could not be categorised under the above, such as wood from broken down fences.

Graffiti was coded as:

- Small tag - small individual identifier (text or symbol), typically with marker pen

- Large tag - larger individual identifier, (text or symbol) typically with paint

- Unofficial mural - picture, typically with paint

- Abusive language - sexist, racist, homophobic, expletives etc.

- Other - slogans or other writing

Photos were taken of each incidence of rubbish/graffiti, which allowed for coding to be checked by a supervisor. Note that this approach focused on the presence or absence of an incidence of rubbish/graffiti and recording this allowed the researchers to identify incidents of rubbish / graffiti that had been removed following the operation, rubbish/ graffiti that had not been removed and rubbish / graffiti that was new following the pre-operation fieldwork. However, recording in this way did not account for changes in the size of piles of rubbish which could grow or diminish between the pre and post observations.

Issues over inter-rater reliability were avoided in the environmental clean-up studies by ensuring that the same researchers were used in the pre and post stages. This helped to ensure that each time, the same geographical area was covered and items were measured in the same way. items were being measured in the same way each time and ensured that the same geographical area was covered each time. However, Brown and Evans (2011) noted the potential for bias caused by researchers knowing whether fieldwork was being undertaken pre or post intervention, with the potential for them to rate differently on the basis of this knowledge. There also remained the possibility of poor inter-rater reliability between studies (despite similar training to all researchers). This potential problem proved difficult to address.

\section{Generalisability}

Generalisability has been recognised as a particular problem in qualitative, observational studies (Maxfield \& Babbie, 2005), due to the often very specific context within which studies are undertaken. This can call into question the extent to which similar results would be found if the study were to be repeated elsewhere. In the studies examined in this paper, generalisability was hard to judge. Where the night-time economy studies were concerned, although undertaken in a very specific context (a town centre in the north-east of England), the universality of the changes to licensing practice suggest that the findings would have been replicated elsewhere. Indeed, other studies of the 
impact of the Licensing Act (2003) found similar results (Hewitt \& Kirby, 2011; Hough \& Hunter, 2008; Morleo, Harkins, Hughes, Hughes \& Lightowlers, 2007; Pike, O'Shea \& Lovbakke, 2008). There was, however, a question over the extent to which SSO conducted over four weekends in the first study and over just one weekend in the second were generalisable to other weekends in the year.

The environmental clean-up studies were similar in that they each involved activity by public servants to clear away rubbish and clean off graffiti in deprived areas made up largely of social housing. It would therefore follow that the findings would only be generalizable to similar types of areas subject to similar intervention of this kind. For example, similar results might not have been obtained had more affluent areas been targeted, or (as Brown and Evans (2011) suggested) had recruited local community members to undertake the clean-up work.

\section{Experiences of employing SSO in the field}

A number of practical lessons were learned during the course of undertaking SSO. These were the kind of lessons not normally found in text books, but which nevertheless had to be negotiated to complete the fieldwork successfully.

\section{Maintaining the role of complete observer}

In undertaking the night-time economy studies, the researchers intended to take on the role of complete observers (Hagan, 1982), involving minimal interaction with those under observation. However, it became clear that, despite attempts to remain unobtrusive, the researchers were noticed, especially by pub/club door-staff. This was, perhaps, inevitable, given that the fieldwork involved walking past such venues every 30 minutes. This initially raised suspicions about the researchers' behaviour, especially among the door-staff of some of the less salubrious clubs. Thus, while patrons appeared oblivious to the presence of researchers (who might only see the researchers once) the repetitive nature of the fieldwork drew attention from the more observant of the town centre's capable guardians. This was addressed by engaging with door-staff of each pub/club early in the evening to explain that a study was being undertaken for the local council. An added benefit of this engagement was that it also allowed the researchers to negotiate access to pub toilets at a time when all other public conveniences were closed. Indeed, this was a practical issue that had not been foreseen in advance.

Between tours of the night-time economy area, the researchers sat in a car just outside the fieldwork area and wrote up their notes from the previous round. On one occasion, the researchers parked on the opposite side of the road from a quiet pub that was not included in the study area. Towards the end of the evening, the researchers were confronted by an irate publican, who assumed that they were (clearly not very good) undercover officers from Her Majesty's Revenue and Customs, checking up on his 
business. On another occasion, the researchers returned to their car to find two women in stiletto healed shoes dancing on the bonnet of their car.

The importance of covering the same ground

The environmental clean-up studies typically involved walking the streets and alleyways of a wide area, sometimes covering as many as 2,000 households. There were times when, on the post implementation sweep, new alleys would be found that were not included in the first sweep. In such cases, it was important to retrace the original trail as faithfully as possible, even if this resulted in incomplete coverage of the area both pre and post intervention.

\section{Fatigue}

The SSO studies described here involved a considerable amount of walking - whether it be recording environmental problems on a housing estate or repeated circuits of a town centre. In both cases, researchers could often expect to walk in excess of ten kilometres during the course of a fieldwork session. In the case of the night-time economy studies, there was the added fatigue of working into the early hours of the morning.

\section{Weather}

Researchers needed to be equipped for all weather conditions, including sunshine, rain and, extreme cold, each of which could affect health and safety working conditions. From the SSO perspective, weather conditions could have a significant impact on observed subjects. For example, it rained heavily on the first evening of the night-time economy fieldwork and this influenced the number of people that were observed on the street.

\section{Benefits of SSO}

The key benefit derived from the use of SSO in the studies described here was the ability to derive measures that were not available from other sources. In the case of the night-time economy studies, the SSO approach yielded a range of findings that would otherwise have not been possible. This included showing how the numbers of people on the street increased during the evening, peaking at midnight, before declining steadily. Following the introduction of later closing of pubs/clubs (by an average of two hours) the decline in numbers occurred over a longer period, so that when the last clubs closed, there was a less pronounced increase in people on the streets. Interestingly the results showed that women tended to leave the area earlier than men, creating a change in the gender mix towards the end of the evening. 
The findings from the SSO were also used to counter claims from licensees that people were simply arriving in the town centre two hours later than they were before and then staying two hours later, effectively shifting the entire night-time economy window by two hours. However, the results of the observation showed that people arrived in the town centre at a similar rate after the licensing changes as they had before.

The findings also demonstrated the detrimental impact on the immediate environment caused by the increase in alcohol and take away food litter over the course of the evening, as well as the more unpleasant prevalence of vomiting and public urination. Indeed, it was estimated that, along the 800 metres of road that formed the night-time economy area, there were 1,040 instances of vomiting per year and 1,092 instances of public urination per year. Other methods were unlikely to yield results of this kind.

Where the evaluations of environmental clean-up operations were concerned, Community Safety Partnerships, typically responsible for undertaking such activities, tended to measure success through an output measure of how much rubbish was removed. It was simply assumed that removing rubbish would necessarily improve the environment. The SSO approach used in these studies provided an objective measure of outcome - the net impact on the amount of rubbish in public spaces. Brown and Evans (2012) reported how, across the ten clean-up operations evaluated, the amount of rubbish observed actually increased by $3 \%$. Indeed, while the cleanliness of the environment improved for five areas, it deteriorated for the remaining five. This was a completely counter-intuitive result, implying that cleaning up an area could actually make it dirtier. Brown and Evans explained this increase in rubbish on the opportunity taking behaviour of the local residents who lived in the areas subject to the clean-ups. Observing that the local authorities were removing rubbish from public spaces, some local residents decided to throw out into the street and on to parkland unwanted items that would otherwise be difficult to take to a refuse tip or would incur a charge from the council for disposal. This was evidenced by the fact that the number of bulky items observed during the post clean-up environmental audits increased.

Similar results could be observed for graffiti. In one case, the amount of graffiti tagging was found to increase from 43 instances before the clean-up to 79 afterwards, an increase of $84 \%$ in the space of just two weeks. On further investigation, it transpired that a professional graffiti artist had been hired as a diversion activity for young people during the school holiday week in which the clean-up operation was undertaken. The artist had worked with the young people on removable boards in the local community centre. This activity seemed to inadvertently encourage participants to practice their newly acquired skills in other parts of the area.

The development of bespoke software for conducting the visual audits allowed for the automatic creation of a report on each incident that included a photo, map and description. This documentation proved extremely powerful when reporting back to a local government client about the cleanliness of the area they had just cleaned. The photographic evidence proved difficult to dispute, despite claims over the amount of rubbish that had been removed. 


\section{By-products of SSO}

In addition to the benefits of SSO listed above, there were a number of additional byproducts derived from observing the environment in which the studies were based, which, while in no way systematic, provided useful context. One such observation related to the use of take-away establishments in Hartlepool town centre. At the end of the evening, once bars and nightclubs had closed, it was common for people to buy take-away food for the journey home. One such take-away establishment seemed to be more popular than others because they turned their music up when the clubs closed to encourage customers to continue their evening in and around the establishment. When this was later raised with the council Licensing Officer he was unaware of the practice and explained that this would clearly be in contravention of the take-away establishment's license to operate.

The use of SSO to count the amount of alcohol related litter in the night-time economy area showed how such litter could lead to people injuring themselves. During the evening, customers would stand outside the pubs in the area and, on finishing their drinks, would sometimes place the empty bottles and glasses close to the pub's wall. However, others would later pass that place and accidentally kick and smash those items, creating a carpet of broken glass that was not cleared away. Indeed, the count of alcohol related litter actually declined towards the end of the evening due to this. At the end of the evening, some women would leave the clubs bare-footed with shoes in hand, no doubt to ease their aching feet after a night of dancing. On several occasions this was observed to lead to cuts to the feet as a result of walking on broken glass.

It was also observed that raised brick flower beds, constructed between the pavement and the road on one side of the street, created a number of problems for the night-time economy. First, the bushes and trees planted in those flower beds cast shadows, creating darkness along the pavement in that location and obscuring natural surveillance. Unsurprisingly, it was noted that more public urinations tended to occur on that side of the street, as did more of the fights. Second, the brick flower beds were also used as seating for those drinking on the street and as unofficial litter bins. As a result of these observations, the flower beds were later removed by the council.

\section{Conclusions}

This paper has examined the experiences of undertaking simple SSO studies to evaluate the impact of two different types of initiatives - changes to licensing regulations on a local night-time economy and the implementation of environmental clean-up operations. Where the night-time economy studies were concerned, the fieldwork involved recording a range of information every 30 minutes over the course of the evening. The environmental clean-up studies involved recording levels of rubbish and graffiti both before and after the intervention.

Both sets of studies showed how information could be collected to show the impact of initiatives, even when other forms of data collection were not possible, producing results that provided valuable insights. In the case of the night-time economy studies, 
there were also a number of additional observations that, while not systematic, provided useful contextual information.

However, it is noted that there are particular challenges to be faced in the field, including how researchers interact with research subjects, fatigue and external conditions (such as imposed by the weather), which mean that SSO is not for the faint hearted. It is also important to note that SSO will not be suitable in all conditions. The studies described here benefited from the fact that the context for the research focused on open street areas and did not involve the direct recording of the behaviour of individuals. Such work has been undertaken in policing research (Mastrofski et al. 1998, 2010; McCluskey \& Terrill, 2005; Schelnberg, 2014; Terrill \& Reisig, 2003), but brings with it a greater set of research problems to be addressed, including negotiating organisational access, informed consent of participants and avoiding Hawthorne effects (Landsberger, 1958) that can derive from the presence of a researcher. These problems may be insurmountable in some circumstances, meaning that there are likely to be conditions in which SSO techniques may not be appropriate. For example, this could be the case when observation involves vulnerable people who are unable to give informed consent, or where the presence of the researcher may alter the dynamics of the situation to the extent that they impede the processes being examined. These problems clearly point to the need to be mindful of the circumstances in which SSO may be employed. Indeed, as with any research method, the choice of SSO will depend on an assessment of the benefits derived from the knowledge gained against the costs in terms of both resource expenditure and impact on research subjects. Nevertheless, there will be circumstances in which SSO provides a valuable contribution to an evaluation, which would not have been possible from employing other methods.

\section{References}

Briesch, A. M., Chafouleas, S. M., \& Riley-Tillman, T. C. (2010). Generalizability and dependability of behaviour assessment methods to estimate academic engagement: A comparison of systematic direct observation and direct behaviour rating. School Psychology Review, 39(3), pp. 408-421.

Brown, R., \& Evans, E. (2011). Four years after the Licensing Act 2003: A case study of Hartlepool town centre. Safer Communities Journal, 10(1), pp. 39-46.

Brown, R., \& Evans, E. (2012).When intervention is a load of rubbish: Evaluating the impact of 'clean-up' operations. Crime Prevention and Community Safety Journal, 14(1), pp. 33-47.

Fetterman, D.M. (2010). Ethnography: step-by-step, Applied Social Research Method Series, Vol. 17. Thousand Oaks, California, USA: Sage Publications.

Hagan, F.E. (1982). Research methods in criminal justice and criminology, New York, NY: Macmillan Publishing. 
Hadfield, P. (2006). Bar wars: Contesting the night in contemporary British cities, Oxford, UK: Oxford University Press.

Hewitt, L., \& Kirby, S. (2011). The impact of the Licensing Act 2003 on drinking habits, offences of crime and disorder and policing in England's newest city. Safer Communities Journal, 10(1), pp. 31-38.

Homel, R., Carvolth, R., Hauritz, M., Mcllwain, G., \& Teague, R. (2004, March). Making licensed venues safer for patrons: What environment factors should be the focus of interventions? [Special Section: Prevention]. Drug and Alcohol Review, 23, pp. 19-29.

Hough, M., Hirschfield, A., \& Newton, A, (2008). The impact of the Licensing Act 2003 on levels of crime and disorder: evaluation methods, Research Report 04, Appendix B. London: Home Office. Retrieved from http://modgov.sefton.gov.uk/ moderngov/documents/s539/Government\%20evaluation\%20of\%20LA03\%20 Report\%20Annex\%202.pdf

Hough, M., \& Hunter, G, (2008). The 2003 Licensing Act's impact on crime and disorder: an evaluation. Criminology and Criminal Justice, 8(3), pp. 239-260.

Landsberger, H. A. (1958). Hawthorne Revisited, New York: Ithaca.

McCluskey, J. D., \& Terrill, W. (2005). Departmental and citizen complaints as predictors of police coercion. Policing: An International Journal of Police Strategies \& Management, 28(3), pp. 513-529.

Mastrofski, S. D., Parks, R. B., Reiss, A. J. Jnr, Worden, R. E., DeJong, C., Snipes, J. B., \& Terrill, W. (1998). Systematic observation of public police: Applying field research methods to policy issues, Washington, DC: National Institute of Justice.

Mastrofski, S. D., Parks, R. B., \& McClusky, J. D. (2010). Systematic social observation in criminology. In A. R. Piquero \& D. Weisburd (Eds), Handbook of Quantitative Criminology (pp. 225-226). New York: Springer.

Maxfield, M., Babbie, E. (2005). Research methods for criminal justice and criminology, (4th Ed.). Belmont, CA: Wadsworth Thomson.

McCall, G. (1978). Observing the law: Field methods in the study of crime and the criminal justice system. New York, NY: Free Press.

Miller, P., Tindall, J., Sønderlund, A., Groombridge, D., Lecathelinais, C., Gillham, K., \& Wiggers, J. (2012). Dealing with alcohol-related harm and the night-time economy, (DANTE) [Final report Monograph Series No. 43], Canberra, ACT: National Drug Law Enforcement Research Fund (NDLERF). Retrieved from http://www.google.com/url?url=http://www.ndlerf.gov.au/sites/default/files/ publication-documents/monographs/monograph43. 
Morleo, M., Harkins, C., Hughes, K., Hughes, S., \& Lightowlers, C. (2007). The implementation and impact of the Licensing Act 2003 in Lancashire. Retrieved from http://www.cph.org.uk/wp-content/uploads/2012/08/the-implementationand-impact-of-the-licensing-act-2003-in-lancashire.pdf

Odgers, C. L., Caspi, A., Bates, C. J., Sampson, R. J., \& Moffitt, T. E. (2012). Systematic social observation of children's neighborhoods using Google Street View: a reliable and cost-effective method, Journal of Child Psychology and Psychiatry, 53(10), pp. 1009-17.

Pike, S., O'Shea, J., \& Lovbakke, J. (2008). Early experiences of the Licensing Act 2003 in the East of England and Yorkshire and the Humber regions, (Research Report 05). London, UK: Home Office.

Reiss, A.J. Jnr. (1971). Systematic observation of natural phenomena. Sociological Methodology, 3(1), pp. 3-33.

Sampson, R. J., \& Raudenbush, S. W. (1999). Systematic social observation of public spaces: A new look at disorder in urban neighbourhoods. American Journal of Sociology, 105(3), pp. 603-651.

Sampson, R. J., Morenoff, J. D., \& Gannon-Rowley, T. (2002). Assessing "Neighbourhood Effects": Social Processes and New Directions in Research. Annual Review of Sociology, 28, pp. 443-478.

Schulenberg, J. L. (2014). Systematic social observation of police decision-making: The process, logistics, and challenges in a Canadian context. Journal of Quality and Quantity, 48(1), pp. 297-315.

Sim, M., Morgan, E., \& Batchelor, J. (2005), The impact of enforcement on intoxication and alcohol related harm, Wellington, NZ: Accident Compensation Corporation.

Smith, L., Morgan, A., \& McAtamney, A. (2011), Policing licensed premises in the Australian Capital Territory, (Technical and Background Paper No. 48). Canberra, ACT: Australian Institute of Criminology.

Terrill, W., \& Reisig, M. D. (2003).Neighbourhood context and police use of force. Journal of Research in Crime and Delinquency, 40(3), pp. 291-321.

Wilcox, P., Augustine, M. C., \& Clayton, R. R. (2006). Physical environment and crime and misconduct in Kentucky schools. Journal of Primary Prevention, 27(3), pp. 293-313.

Zarrett, N., Sorensen, C., \& Skiles, B. (2010). Environmental and social-motivational contextual factors related to youth physical activity: systematic observations of summer day camps. International Journal of Behavioural Nutrition and Physical Activity, 10(63), pp. 1-13. 